\title{
Effect of Mesh Electrodes Geometry on the Ozone Concentration in the Presence of Micanite Dielectric
}

\author{
Ernest Gnapowski'
}

1 Department of Transport, University College of Enterprise and Administration, Bursaki 12, 20-150 Lublin, Poland, e-mail: egnapowski@gmail.com

\begin{abstract}
The manuscript presents experimental research on a plasma reactor with two mesh electrodes and a micanite dielectric. Three types of electrode geometry were used in experimental research; mesh size $0.1 \times 0.1 \mathrm{~mm}, 0.3 \times 0.3 \mathrm{~mm}$ and perforated electrodes with $\varnothing 1.38 \mathrm{~mm}$ holes. The results of experimental research show the influence of electrode geometry on the ozone generation process. The use of electrodes perforated with $\varnothing 1.38 \mathrm{~mm}$ holes generates $20 \%$ lower ozone concentration, compared to the configuration with two mesh electrodes size $0.1 \times 0.1 \mathrm{~mm}$ at the same power of discharges.
\end{abstract}

Keywords: ozone, DBD discharge, mesh electrodes, micanite dielectric.

\section{INTRODUCTION}

The first plasma reactors had simple designs. The most popular dielectrics are glass and flat metal electrodes. Insulating Kapton film, ceramics, micanite, and other dielectric materials are used in experimental models of ozone generators. The use of a dielectric in a plasma reactor allows to obtain barrier discharges (DBD) and prevents arcing and increasing the local temperature resulting from decreased concentration and ozone generation efficiency. There are many factors that affect the operation of the reactor; supply voltage [1], type of gas used [2], electrode geometry [3], discharge gap and type of dielectric [4-6]. The manuscript presents the results of experimental studies on the effect of electrode geometry on ozone concentrations. Three types of electrode geometry were used in experimental research; mesh size $0.1 \times 0.1 \mathrm{~mm}, 0.3 \times 0.3 \mathrm{~mm}$ and perforated electrodes with $Ø 1.38 \mathrm{~mm}$ holes, micanite dielectric thickness of $1.0 \mathrm{~mm}$ and $2.0 \mathrm{~mm}$ discharge gap. Optimizing the operation of DBD systems is important. Ozone is increasingly often used in everyday life and industry [6-7]; thus, it is necessary to increase the efficiency of DBD systems.

\section{MATERIALS AND METHODS}

Experimental research was carried out using the plasma reactor shown in Fig. 1a. The autotransformer and transformer $\mathrm{HV}$ were used to power supply the plasma reactor. The operating parameters of the reactor were measured using Tektronix TDS 2024B oscilloscope, Tektronix P6015A high voltage probes, Tektronix P2220 current probe. The concentration of ozone was measured using BMT 961TC ozone analyzer and Bronkhorst F-201CV-1K0-AAD-44-V flowmeter was used to regulate the flow. In the experimental research, a reactor with two mesh electrodes separated by a micanite solid dielectric was used. The construction of the plasma reactor allows reactor operation in two configurations; the first when a porous dielectric is used, the gas passes through the HV electrode, then the porous dielectric and the grounded electrode. The second configuration allows the use of a solid dielectric impermeable to gas. In this configuration, one mesh electrode is permeable to gas, and a solid dielectric is placed on the second electrode. The system operated in the second configuration to carry out the investigations described in the 

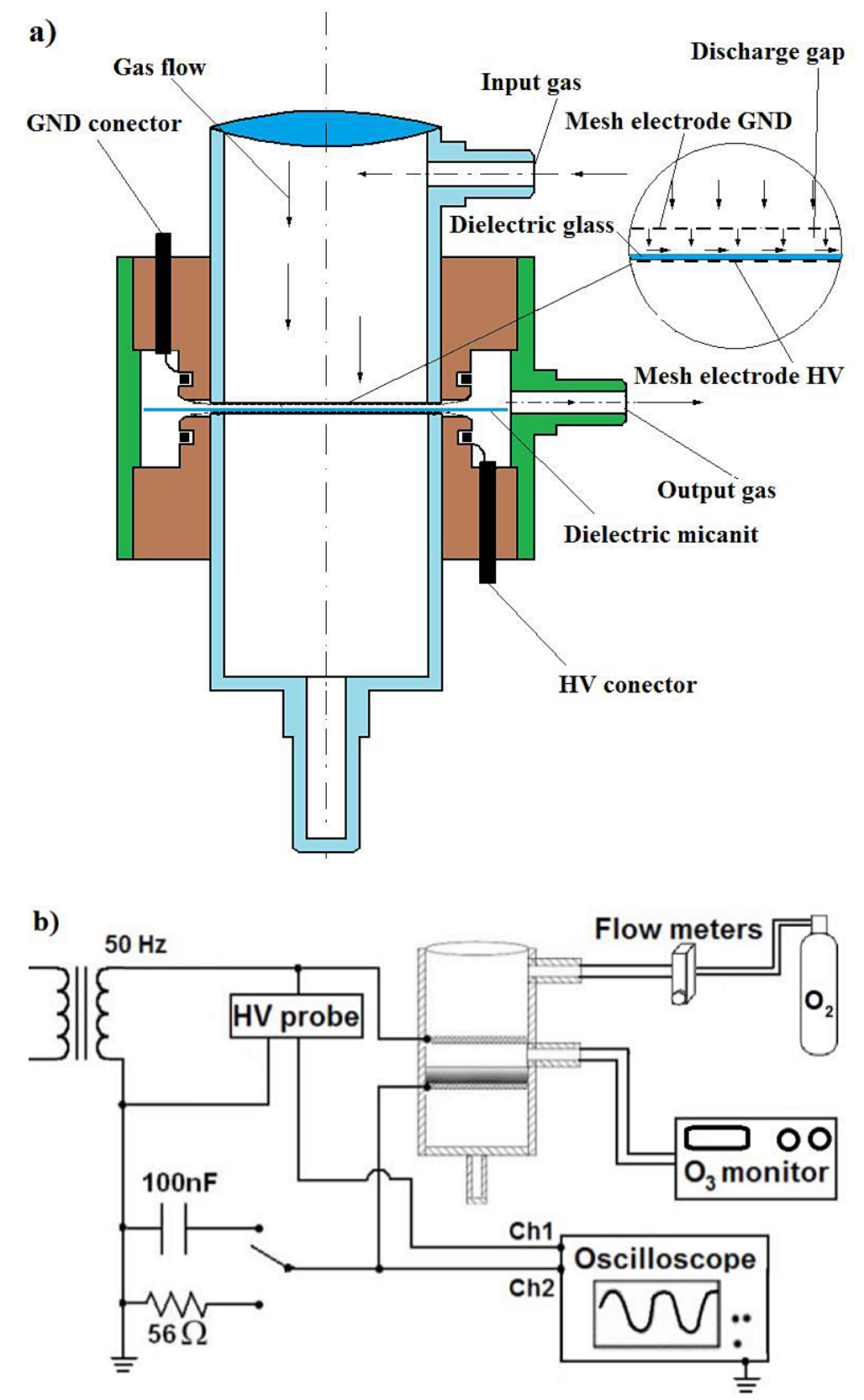

Fig. 1. Schematic diagram ; a) plasma reactor, b) measuring system.

publication. Experimental studies were carried out with micanite dielectric thickness of $1.0 \mathrm{~mm}$.

The applied micanite dielectric is impermeable to gas. It was placed on the surface of one electrode, as shown in Figure 2. The parameters of the reactor geometry and operating conditions are shown in Table 1.

The experimental research was carried out using mesh electrodes with mesh size $0.1 \times 0.1 \mathrm{~mm}$, $0.3 \times 0.3 \mathrm{~mm}$, perforated sheet with $\varnothing 1.38 \mathrm{~mm}$ holes and micanite dielectric thickness of $1.0 \mathrm{~mm}$.

\section{RESULTS AND DISCUSSION}

The first series of research was performed for $0.1 \times 0.1 \mathrm{~mm}$ mesh electrodes for micanite dielectric and 2.0 discharge gap for $0.5 \mathrm{l} / \mathrm{min}$ oxygen flow. In order to calculate the power of discharges, the Lissajous figures recorded during the reactor operation were used. Selected Lissajous figures are shown in figure 3. During the research, ozone concentration was recorded for individual voltage ranges from $6800 \mathrm{~V}$ to $11500 \mathrm{~V}$. 


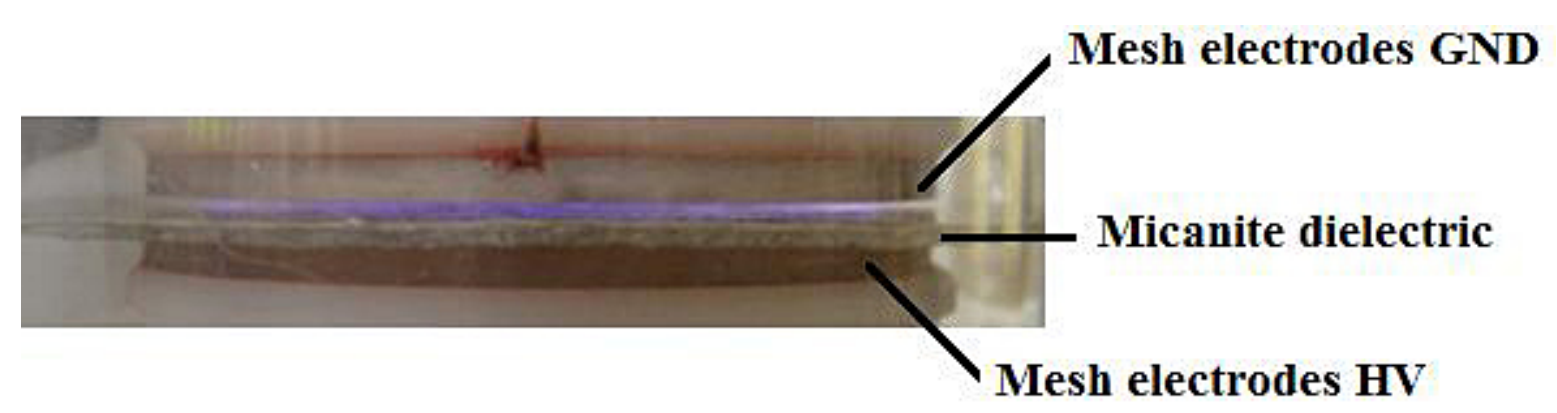

Fig. 2. Micanite dielectric configuration

Table 1. Parameters of the experiments

\begin{tabular}{|l|c|}
\hline \multicolumn{1}{|c|}{ Parametr } & Settings used \\
\hline Surface of electrode, $\mathrm{cm}^{2}$ & 18.8 \\
\hline Gap, $\mathrm{mm}$ & 2.0 \\
\hline Frequency, $\mathrm{Hz}$ & 50 \\
\hline Process gas flow, $\mathrm{L} \cdot \mathrm{min}^{-1}$ & 0.5 \\
\hline Gas & Oxygen \\
\hline Micanite dielectric, $\mathrm{mm}$ & 1 \\
\hline
\end{tabular}

The maximum concentration of ozone obtained for the micanite dielectric was $2.60 \mathrm{~g} \mathrm{O}_{3} / \mathrm{m}^{3}$.

Another research was performed for mesh electrodes with mesh electrodes $0.3 \times 0.3 \mathrm{~mm}$, micanite dielectric and $2.0 \mathrm{~mm}$ discharge gap. The changes in the discharge power were calculated using the Lissajous figures; the selected ones were shown in figure 4 .
The maximum power obtained for micanite dielectric and mesh electrodes $0.3 \times 0.3 \mathrm{~mm}$ was $0.80 \mathrm{~W}$ with ozone concentration $2.40 \mathrm{gO}_{3} / \mathrm{m}^{3}$.

The last research was performed for perforated electrodes with $\varnothing 1.38 \mathrm{~mm}$ holes. The Lissajous figure at supply voltage $\mathrm{V}=10200 \mathrm{~V}$ is shown in figure 5 .

The maximum discharge power for micanite dielectric and electrodes with $\varnothing 1.38 \mathrm{~mm}$ holes was $0.92 \mathrm{~W}$ with an ozone concentration of $1.98 \mathrm{gO}_{3} / \mathrm{m}^{3}$

\section{ANALYSIS OF THE RESULTS OBTAINED}

The analysis of the obtained results allows to determine the influence of electrode geometry on the concentration of ozone. The selected pa-

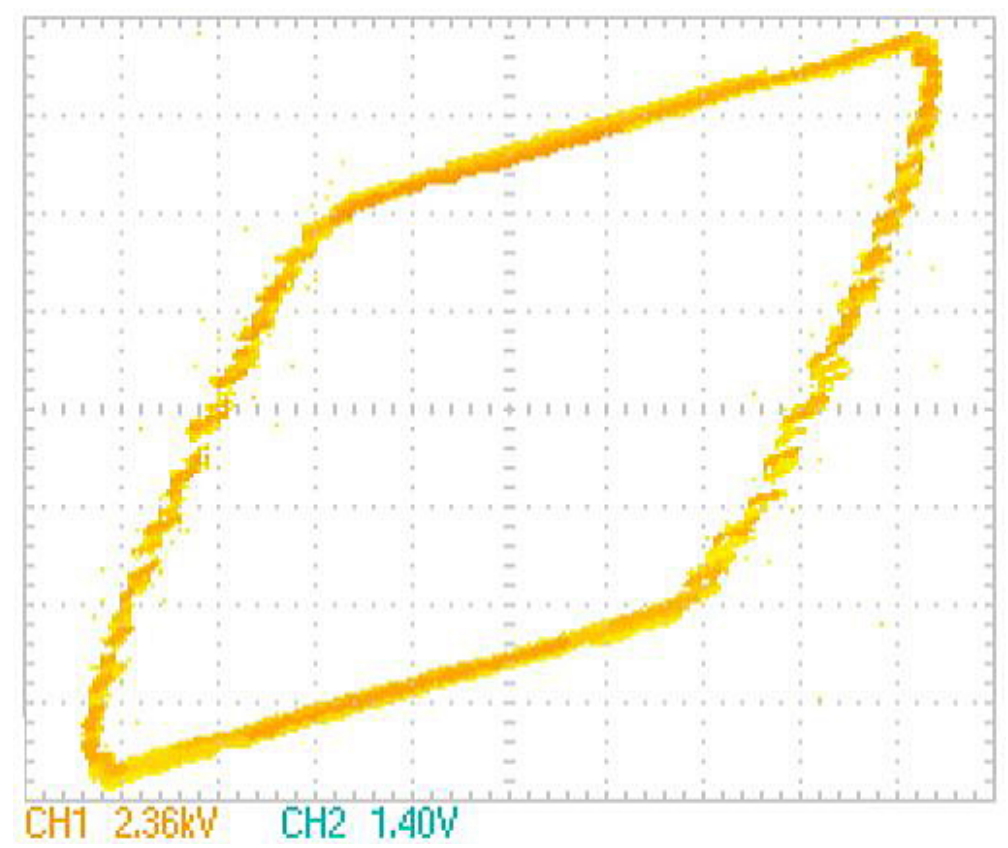

Fig. 3. Lissajous figures for micanite dielectric for discharge gap $2.0 \mathrm{~mm}, 0.1 \times 0.1 \mathrm{~mm}$ mesh electrodes, at supply voltage $\mathrm{V}=9900 \mathrm{~V}$. 


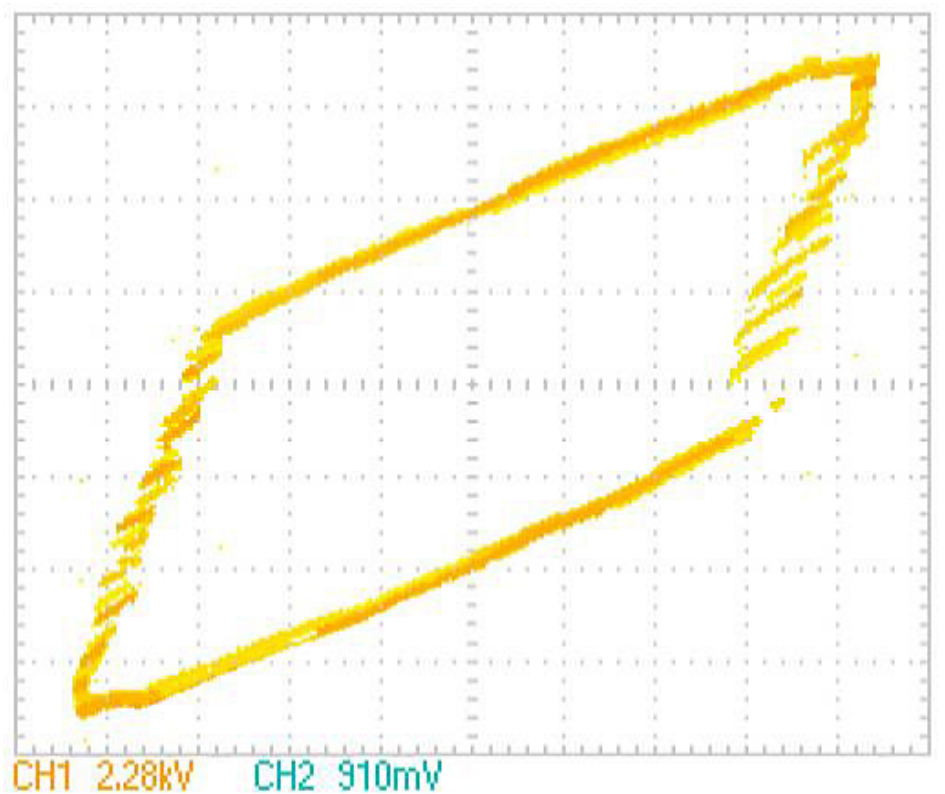

Fig. 4. Lissajous figures for micanite dielectric for discharge gap $2.0 \mathrm{~mm}, 0.3 \times 0.3 \mathrm{~mm}$ mesh electrodes, at supply voltage $\mathrm{V}=9600 \mathrm{~V}$.

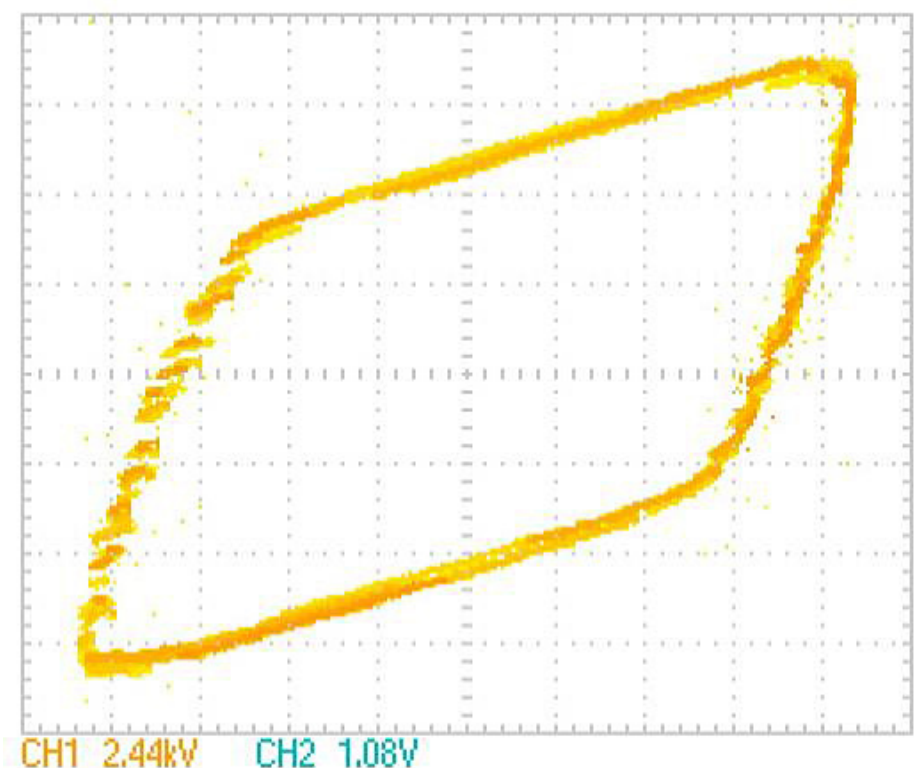

Fig. 5. Figure Lissajous figures for micanite dielectric for discharge gap $2.0 \mathrm{~mm}$, electrodes with holes $Ø 1.38$ $\mathrm{mm}$, at supply voltage $\mathrm{V}=10200 \mathrm{~V}$.

rameters and experimental results are shown in table 2. Determination of the influence of electrode geometry on ozone concentrations was compared to the results obtained for individual electrodes. Figure 6 presents a comparison of ozone concentration for the micanite dielectric and mesh electrodes; $0.1 \times 0.1 \mathrm{~mm}, 0.3 \times 0.3 \mathrm{~mm}$ and perforated with $Ø 1.38 \mathrm{~mm}$ holes for discharge gap $2.0 \mathrm{~mm}$.

The analysis of the data contained in Table 2 and figure 6 shows the effect of electrode geometry on the generation of ozone. The smallest ozone concentration was obtained for the electrodes perforated with $\varnothing 1.38 \mathrm{~mm}$ holes and was equal to $1.98 \mathrm{gO}_{3} / \mathrm{m}^{3}$ at power $0.92 \mathrm{~W}$.

The highest ozone concentration of $2.60 \mathrm{gO}_{3} / \mathrm{m}^{3}$ was obtained for mesh electrodes $0.1 \times 0.1 \mathrm{~mm}$ and power $0.97 \mathrm{~W}$, a similar ozone concentration of $2.40 \mathrm{gO}_{3} / \mathrm{m}^{3}$ and power $0.80 \mathrm{~W}$ obtained for mesh electrodes $0.3 \times 0.3 \mathrm{~mm}$. 


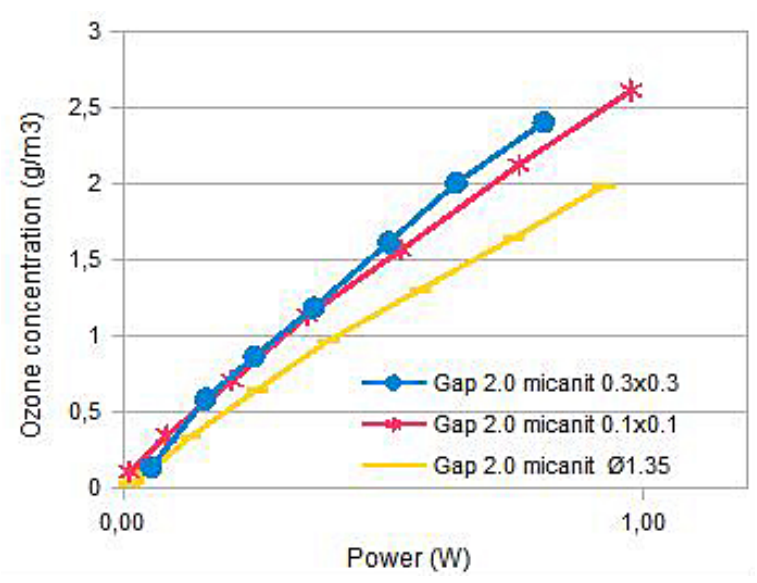

Fig. 6. Comparison of ozone concentration obtained for three configurations electrodes; mesh electrodes

$0.1 \times 0.1 \mathrm{~mm}, 0.3 \times 0.3 \mathrm{~mm}$ and electrodes with $\varnothing 1.38 \mathrm{~mm}$ holes.

Table 2. Measurement results for mesh electrodes, micanite dielectric and $2.0 \mathrm{~mm}$ discharge gap.

\begin{tabular}{|c|c|c|c|}
\hline $\begin{array}{c}\text { Voltage range, } \\
\mathrm{V}\end{array}$ & $\begin{array}{c}\text { Maximum } \\
\text { power, } \mathrm{W}\end{array}$ & $\begin{array}{c}\text { Concentration } \\
\mathrm{O}_{3}, \mathrm{gO}_{3} / \mathrm{m}^{3}\end{array}$ & $\begin{array}{c}\text { Electrodes, } \\
\mathrm{mm}\end{array}$ \\
\hline $7900 \div 12500$ & 0.80 & 2.40 & $0.3 \times 0.3$ \\
\hline $6800 \div 11500$ & 0.97 & 2.60 & $0.1 \times 0.1$ \\
\hline $6800 \div 12700$ & 0.92 & 1.98 & $\varnothing 1.38$ \\
\hline
\end{tabular}

\section{CONCLUSION}

The analysis of experimental results obtained for a reactor with two mesh electrodes indicates the effect of electrode geometry on the ozone generation process. The obtained concentration of ozone for a plasma reactor with two electrodes perforated with $\varnothing 1.38 \mathrm{~mm}$ holes is $20 \%$ lower compared to the concentration of ozone obtained for a reactor with two mesh electrodes $0.1 \times 0.1 \mathrm{~mm}$; the discharge power had similar values. The lower concentration of ozone obtained for electrodes perforated with $\varnothing 1.38 \mathrm{~mm}$ holes is associated with streamer discharges. A larger number of streamer discharges is caused with an "edge effect". The length of the discharge gap and holes in perforated electrodes having sharp edges increase this effect. Experimental research shows the effect of electrode geometry on the ozone concentrations. The small mesh size of the mesh electrodes and small discharge gap, allow to obtain homogeneous discharges [5,7] and higher concentration of ozone.

\section{REFERENCES}

1. Höft H., Becker M. M., Loffhagen D. Kettlitz M., On the influence of high voltage slope steepness on breakdown and development of pulsed dielectric barrier discharges, Plasma Sources Science and Technology, Vol. 25, Nr. 6, 2016.

2. Fang Z., Shao T., Ji S., Pan J., Zhang C., Generation of Homogeneous Atmospheric-Pressure Dielectric Barrier Discharge in a Large-Gap Argon Gas, IEEE Transactions on Plasma Science, 2012, Vol. 40 , Issue: 7, $1884-1890$.

3. Gnapowski E., Gnapowski S., Pytka J., Effect of Mesh Geometry on Power, Efficiency and Homogeneity of Barrier Discharges in the Presence of Glass Dielectric, IEEE Transactions on Plasma Science, Vol. 46, 2018, 3493 - 3498.

4. Brandenburg R., Dielectric barrier discharges: progress on plasma sources and on the understanding of regimes and single filaments, Plasma Sources Science and Technology, 2017, Vol. 26, Nr 5.

5. Gnapowski E., Gnapowski S., Changes in the Power Discharge in a Plasma Reactor Using Porous Versus Solid Dielectric Barriers and Meshes Electrodes, IEEE Transactions on Plasma, Vol. 44 Issue: 10, 2016, 2079- 2083.

6. Gnapowski E., Gnapowski S., Pytka J., The impact of dielectrics on the electricalcapacity, concentration, efficiency ozonegeneration for the plasma reactor with meshelectrodes, Plasma Science and Technology, 2018, Vol. 20, Nr 8, 1-7

7. Baumgärtner H., FuenzalidaV.,Eisele I., Ozone cleaning of the $\mathrm{Si}-\mathrm{SiO} 2$ system, Applied Physics A. Solids and Surfaces, Vol. 43, 1987, 223-226.

8. Gnapowski S., Gnapowski E., Duda A., Inproving of the quality food for animals by pulsed power plasma discharge, Advances in Science and Technology Research Journal, Vol. 9, No. 27, 2015, 58-65.

9. Benard N., Moreau E., Electrical and mechanical characteristics of surface AC dielectric barrier discharge plasma actuators applied to airflow control, Experiments in Fluids, 2014, Vol. 55. 